\title{
EZH2-mediated epigenetic repression of DNA repair in promoting breast tumor initiating cells
}

\author{
Olafur Andri Stefansson ${ }^{1}$ and Manel Esteller ${ }^{* 1,2}$
}

\begin{abstract}
Members of the Polycomb-group (PcG) family of proteins, including EZH2 (enhancer of zeste homolog 2), are involved in establishing epigenetic silencing of developmental genes in adult and embryonic stem cells, and their deregulation has been implicated in cancer. In a recent report, EZH2mediated epigenetic repression of DNA damage repair in breast tumor initiating cells (BTICs) was identified as a mechanism that could promote expansion of BTICs, and may contribute to cancer progression.
\end{abstract}

\section{Background}

EZH2 (enhancer of zeste homolog 2) is a member of the Polycomb-group (PcG) family and encodes a histone methyltransferase that is the catalytic component of the polycomb repressive complex (PCR)2 [1]. The PRC2 complex has a role in establishing methylation marks on histone H3 (triMe-K27 H3) to initiate chromatin condensation and silencing of genes involved in developmental processes [2,3]. PcG proteins are known to be essential in maintaining self-renewal and pluripotency of stem cells [4], and their deregulation has been linked to cancer [5].

The cancer stem cell (CSC) hypothesis proposes that a limited subpopulation of cancer cells has self-renewal capacity and is responsible for tumor growth [6]. According to the CSC hypothesis, progression towards aggressive behavior can ultimately be traced to changes that occur in the CSCs, or tumor initiating cells (TICs). However, experimental data on the molecular changes and the mechanism by which they could occur have been lacking. In breast cancer, stem cell-like properties associate with expression of $\mathrm{CD} 44$, and negativity/low CD24, that is $\mathrm{CD} 44^{+} / \mathrm{CD} 24^{- \text {/low }}$ [7]. Recently, Chang and

\footnotetext{
*Correspondence: mesteller@idibell.cat

${ }^{1}$ Cancer Epigenetics and Biology Program (PEBC), Bellvitge Biomedical Research Institute, 08908 L'Hospitalet, Barcelona, Catalonia, Spain

Full list of author information is available at the end of the article
}

colleagues [8] studied EZH2 in CD44 $/$ CD24-/low cells, or breast tumor initiating cells (BTICs), and described an important link to genomic instability, activation of RAF1$\beta$-catenin signaling, and expansion of the BTIC population.

\section{The article}

Chang and colleagues [8] demonstrate that increased $\mathrm{EZH} 2$ in $\mathrm{CD}_{4} 4^{+} / \mathrm{CD} 24^{- \text {llow }}$ cells correlates with their increased abundance, that is, the proportion of $\mathrm{CD} 44^{+} /$ CD24-/low cells. Increased EZH2 in CD44+/CD24-/low cells was correlated with decreased RAD51 levels. Using chromatin immunoprecipitation (ChIP), the authors show that EZH2, and other PRC1/PRC2 proteins, are recruited to a putative Ploycomb response element on the RAD51 promoter. Here, hypoxia in the microenvironment was identified as a potential cause of EZH2 upregulation. The RAD51 gene has a well established role in DNA repair through homologous recombination and, accordingly, EZH2-mediated epigenetic repression of RAD51 associates with accumulation of DNA damage and chromosome abnormalities.

Using protein arrays, the authors identified increased expression of the RAF1 gene as a potential change associated with EZH2-induced genomic instability. Importantly, this association was found to be a consequence of acquired DNA copy number gains over the RAF1 gene at 3 p25.2, resulting in activation of ERK and $\beta$-catenin, shown to confer survival and proliferative advantages for CD44 $/$ CD24-llow cells. Importantly, inhibition of RAF1MEK-ERK- $\beta$-catenin activation by small molecule inhibitors (AZD6244, Sorafenib) leads to effective elimination of CD44 $/ \mathrm{CD} 24^{-/ \text {low }}$ cells - that is, BTICs - suggesting potential implications with respect to clinical management of the disease.

\section{Viewpoint}

The most important insight from Chang and colleagues [8] is the observation that genomic instability induced by EZH2-mediated epigenetic repression of DNA repair, that is, RAD51, results in expansion of the BTIC population. Further, the order in which these changes occur did not influence the eventual outcome - that is, overexpression of EZH2 has the same effect as knock-down of 
RAD51. In this context, RAF1 amplification was described as a recurrent oncogenic consequence of downregulated DNA repair leading to activation of ERK and $\beta$-catenin and the consequent promotion of the BTIC population. In breast cancer, EZH2 overexpression has previously been linked to aggressive and poorly differentiated carcinomas [9], and downregulated DNA repair [10]. The insights provided by Chang and colleagues relate to the identification of EZH2 in augmenting BTICs through epigenetic repression of DNA repair, leading to aggressive disease. These results are consistent with clonal evolution of CSCs, that is, the notion that aggressive secondary CSCs can arise from the primary population of CSCs. The clinical relevance relates to potential benefits from RAF1/MEK/ERK inhibitors in the treatment of breast cancer patients, and in preventing disease progression. Further, poly ADP ribose polymerase (PARP) inhibitors are highly effective in targeting cancer cells with homologous recombination defects and therefore hold unexplored potential in this regard, that is, in targeting secondary CSCs [11].

Although somatic mutations in DNA repair genes are rare in sporadic cancers, it is well established that susceptibility to cancer is commonly linked to inherited mutations in DNA repair genes, for example, BRCA1, BRCA2, PALB2, WRN and MLH1 [12]. This has led some to speculate that defects in DNA repair genes cannot explain instability in sporadic cancers [12], whereas others have emphasized epigenetic mechanisms [13]. Chang and colleagues [8] describe results suggesting a causative link between epigenetic inactivation of DNA repair, the emergence of genomic instability, and cancer progression. In breast cancer, epigenetic inactivation of the BRCA1 gene occurs through CpG island hypermethylation $[14,15]$. BRCA1 is essential in DNA repair of double-strand breaks, with RAD51 as a crucial partner for error-free repair by homologous recombination [16]. Recently, Lim and colleagues [17] demonstrated that BRCA1 defective breast cancers represent an expanded population of luminal progenitor cells. This is consistent with the results described in Chang and colleagues [8], demonstrating DNA repair defects and expansion of tumor cells with progenitor/stem-cell characteristics. In conclusion, an important task in future research will be to explore the relationship between epigenetic repression of DNA repair, the induction of genomic instability, and markers of CSCs.

\section{Abbreviations}

BTIC, breast tumor initiating cell; CSC, cancer stem cell; PCG, Polycomb-group; $\mathrm{PCR}$, polycomb repressive complex.

\section{Competing interests}

The authors declare that they have no competing interests.

\section{Author details}

'Cancer Epigenetics and Biology Program (PEBC), Bellvitge Biomedical Research Institute, 08908 L'Hospitalet, Barcelona, Catalonia, Spain. Institucio Catalana de Recerca i Estudis Avançats, 08010 Barcelona, Catalonia, Spain.

\section{Published: 25 May 2011}

\section{References}

1. Simon JA, Lange CA: Roles of the EZH2 histone methyltransferase in cancer epigenetics. Mutat Res 2008, 647:21-29.

2. Pasini D, Bracken AP, Hansen JB, Capillo M, Helin K: The polycomb group protein Suz 12 is required for embryonic stem cell differentiation. Mol Cell Biol 2007, 27:3769-3779.

3. Lee TI, Jenner RG, Boyer LA, Guenther MG, Levine SS, Kumar RM, Chevalier B, Johnstone SE, Cole MF, Isono K, Koseki H, Fuchikami T, Abe K, Murray HL, Zucker JP, Yuan B, Bell GW, Herbolsheimer E, Hannett NM, Sun K, Odom DT, Otte AP, Volkert TL, Bartel DP, Melton DA, Gifford DK, Jaenisch R, Young RA: Control of developmental regulators by Polycomb in human embryonic stem cells. Cell 2006, 125:301-313.

4. Rajasekhar VK, Begemann M: Concise review: roles of polycomb group proteins in development and disease: a stem cell perspective. Stem Cells 2007, 25:2498-2510.

5. Huang $\mathrm{TH}$, Esteller M: Chromatin remodeling in mammary gland differentiation and breast tumorigenesis. Cold Spring Harb Perspect Biol 2010, 2:a004515.

6. Clevers $\mathrm{H}$ : The cancer stem cell: premises, promises and challenges. Nat Med 2010, 17:313-319.

7. Al-Hajj M, Wicha MS, Benito-Hernandez A, Morrison SJ, Clarke MF: Prospective identification of tumorigenic breast cancer cells. Proc Nat Acad Sci U S A 2003, 100:3983-3988.

8. Chang CJ, Yang JY, Xia W, Chen CT, Xie X, Chao CH, Woodward WA, Hsu JM, Hortobagyi GN, Hung MC: EZH2 promotes expansion of breast tumor initiating cells through activation of RAF1-beta-catenin signaling. Cancer Cell, 19:86-100

9. Kleer CG, Cao Q, Varambally S, Shen R, Ota I, Tomlins SA, Ghosh D, Sewalt RG, Otte AP, Hayes DF, Sabel MS, Livant D, Weiss SJ, Rubin MA, Chinnaiyan AM: $\mathrm{EZH} 2$ is a marker of aggressive breast cancer and promotes neoplastic transformation of breast epithelial cells. Proc Natl Acad Sci U S A 2003, 100:11606-11611.

10. Zeidler M, Varambally S, Cao Q, Chinnaiyan AM, Ferguson DO, Merajver SD, Kleer CG: The Polycomb group protein EZH2 impairs DNA repair in breast epithelial cells. Neoplasia 2005, 7:1011-1019.

11. McCabe N, Turner NC, Lord CJ, Kluzek K, Bialkowska A, Swift S, Giavara S, O'Connor MJ, Tutt AN, Zdzienicka MZ, Smith GC, Ashworth A: Deficiency in the repair of DNA damage by homologous recombination and sensitivity to poly(ADP-ribose) polymerase inhibition. Cancer Res 2006, 66:8109-8115

12. Negrini S, Gorgoulis VG, Halazonetis TD: Genomic instability - an evolving hallmark of cancer. Nat Rev Mol Cell Biol, 11:220-228.

13. Esteller M: Epigenetic lesions causing genetic lesions in human cancer: promoter hypermethylation of DNA repair genes. Eur J Cancer 2000, 36:2294-2300.

14. Esteller M, Silva JM, Dominguez G, Bonilla F, Matias-Guiu X, Lerma E, Bussaglia E, Prat J, Harkes IC, Repasky EA, Gabrielson E, Schutte M, Baylin SB, Herman JG: Promoter hypermethylation and BRCA1 inactivation in sporadic breast and ovarian tumors. J Natl Cancer Inst 2000, 92:564-569.

15. Birgisdottir V, Stefansson OA, Bodvarsdottir SK, Hilmarsdottir H, Jonasson JG, Eyfjord JE: Epigenetic silencing and deletion of the BRCA1 gene in sporadic breast cancer. Breast Cancer Res 2006, 8:R38.

16. Murphy CG, Moynahan ME: BRCA gene structure and function in tumor suppression: a repair-centric perspective. Cancer J, 16:39-47.

17. Lim E, Vaillant F, Wu D, Forrest NC, Pal B, Hart AH, Asselin-Labat ML, Gyorki DE, Ward T, Partanen A, Feleppa F, Huschtscha LI, Thorne HJ; kConFab, Fox SB, Yan M, French JD, Brown MA, Smyth GK, Visvader JE, Lindeman GJ: Aberrant luminal progenitors as the candidate target population for basal tumor development in BRCA1 mutation carriers. Nat Med 2009, 15:907-913.

doi:10.1186/bcr2871

Cite this article as: Stefansson OA, Esteller M: EZH2-mediated epigenetic repression of DNA repair in promoting breast tumor initiating cells. Breast Cancer Research 2011, 13:309. 